
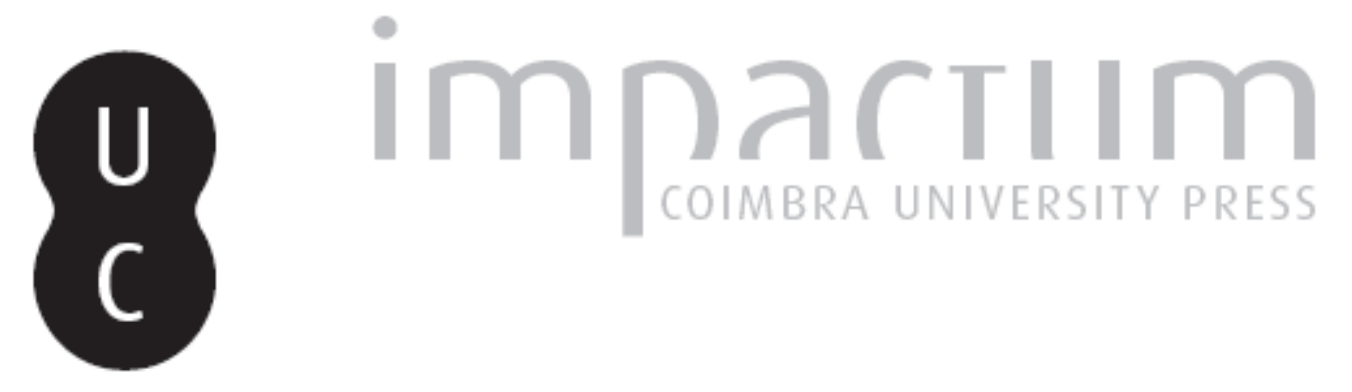

\title{
Conhecimento e virtude no Mênon de Platão
}

\section{Autor(es): $\quad$ Ferrari, Franco}

Publicado por: Annablume Clássica; Imprensa da Universidade de Coimbra

URL persistente:

URI:http://hdl.handle.net/10316.2/27876

DOI:

DOI:http://dx.doi.org/10.14195/1984-249X_12_8

Accessed : $\quad$ 26-Apr-2023 10:00:57

A navegação consulta e descarregamento dos títulos inseridos nas Bibliotecas Digitais UC Digitalis, UC Pombalina e UC Impactum, pressupõem a aceitação plena e sem reservas dos Termos e Condições de Uso destas Bibliotecas Digitais, disponíveis em https://digitalis.uc.pt/pt-pt/termos.

Conforme exposto nos referidos Termos e Condições de Uso, o descarregamento de títulos de acesso restrito requer uma licença válida de autorização devendo o utilizador aceder ao(s) documento(s) a partir de um endereço de IP da instituição detentora da supramencionada licença.

Ao utilizador é apenas permitido o descarregamento para uso pessoal, pelo que o emprego do(s) título(s) descarregado(s) para outro fim, designadamente comercial, carece de autorização do respetivo autor ou editor da obra.

Na medida em que todas as obras da UC Digitalis se encontram protegidas pelo Código do Direito de Autor e Direitos Conexos e demais legislação aplicável, toda a cópia, parcial ou total, deste documento, nos casos em que é legalmente admitida, deverá conter ou fazer-se acompanhar por este aviso.

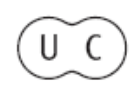


jan/jun

\begin{tabular}{c}
2014 \\
\hline issn 2179-4960 \\
e-issn 1984-249-X
\end{tabular}
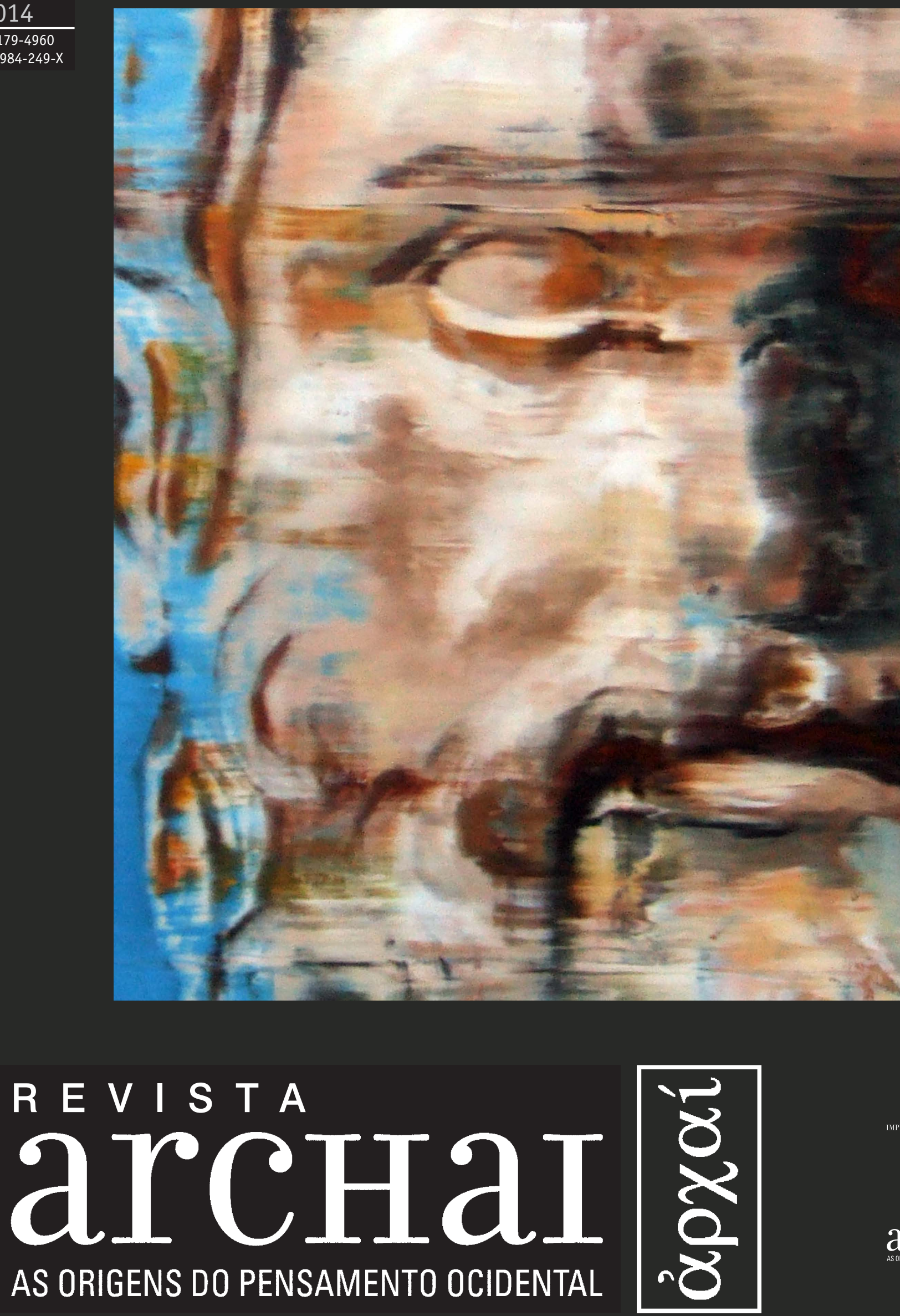
ARCHAI JOURNAL: ON THE ORIGINS OF WESTERN THOUGHT

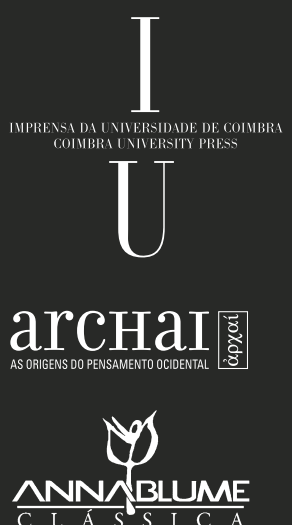




\section{CONHECIMENTO E VIRTUDE NO MÊNON DE PLATÃO}

FERRARI, F. (2014) Conhecimento e virtude no Mênon de Platão. Archai, n. 12, jan - jun, p. 81-87 D0I: http://dx.doi. org/10.14195/1984-249X_12_8

RESUMO: 0 tema da natureza da virtude e de sua transmissibilidade atravessa quase todos os diálogos da juventude de Platão, isto é, os considerados "diálogos socráticos". Este adquire uma relevância central no Protágoras e no Mênon, o qual se abre exatamente com a interrogação acerca da maneira de adquirir a virtude. No curso do diálogo, a arete assume um significado eminentemente político: Mênon pergunta a Sócrates como se pode obter sucesso no campo político, como se pode adquirir reconhecimento social. A tese em torno a qual se desenvolve a conversação assume a identidade de virtude e conhecimento (episteme). Todavia, a consequência que deriva da assunção desta tese, isto é, o princípio com base no qual a virtude, enquanto conhecimento, seja ensinável, é refutado por meio do célebre "argumento empírico": a ausência de homens capazes de transmitir a sua virtude aos filhos demonstra que essa não é ensinável, $e$,portanto, não é conhecimento. Sócrates propõe, então, situar na opinião correta (orthe doxa) a fonte da virtude política. Todavia, a validade do argumento empírico resulta muito incerta, uma vez que parece fundar-se na ambiguidade do significado do termo didakton, que quer dizer seja "ensinável" seja efetivamente "ensinado". Também a tentativa de fundar a virtude na theia moira deve ser tratada com certo ceticismo. Na realidade, Sócrates alude, no fim do diálogo, à possibilidade de que exista um homem que seja virtuoso e que seja também capaz de ensinar a virtude a outro homem: este homem extraordinário é naturalmente o próprio Sócrates.

PALAVRAS-CHAVE: virtude, conhecimento, mestres de virtude, opinião.
* Università degli Studi di Salerno, Salerno, Itália

1. Veja-se a propósito a discussão em Scott (2006)

14-18.

\section{Franco Ferrari*}

1. 0 tema da natureza da virtude (arete) e da maneira de adquiri-la atravessa quase todos os diálogos juvenis de Platão. Está presente no Laques, no Eutífron, no Cármides, no Górgias e de algum modo, na própria Apologia. Mas não há dúvidas que a questão da virtude e o modo como os homens podem obtê-la assume uma relevância central no Protágoras e no Mênon.

Este último diálogo abre, como se nota, precisamente com a formulação, da parte de Mênon, da questão sobre a maneira de adquirir a arete. 0 interlocutor de Sócrates apresenta quatro opções, reciprocamente excludentes entre si: a virtude seria a) ensinável (didakton), ou b) adquirível por meio de exercício (asketon), ou ainda c) nem uma, nem outra coisa, mas sobreviria por natureza (physei) ou d) de algum outro modo (Men. 70 a).

Querendo também prescindir da eventualidade que a referência ao exercício, isto é, à prática, constitua uma inserção textual sucessiva, ausente no original platônico ${ }^{1}$, não há dúvida que a questão de Mênon parece mais estranha, seja na sua forma exclusiva na qual vêm apresentadas as opções, seja em relação ao desenvolvimento do diálogo, que de fato toma em consideração só a primeira opção, relativa à ensinabilidade da virtude, e talvez aponte para a última no final da discussão, quando vem apresentada a hipótese que a virtude 
ABSTRACT: The theme of the nature of virtue and its transmissibility runs through almost all the early dialogues of Plato, that is, the so-called "Socratic dialogues." It acquires a central importance in the Protagoras and Meno, which opens with the question about the way to acquire virtue. During the dialogue, virtue assumes a highly political significance: Meno asks Socrates how we can achieve success in the political field, as we might acquire social recognition. The thesis around which the conversation develops assumes the identity of virtue and knowledge (episteme). However, the consequence which follows from the assumption of this thesis, that is, the principle according to which virtue, because knowledge, is teachable is refuted by the famous "empirical argument": the absence of men able to transmit the their virtues to their children shows that it is not teachable, and therefore not knowledge. Socrates then proposes to locate the source of political virtue in correct opinion (orthe doxa). However, the empirical validity of the argument is highly uncertain, since it seems to be based on the ambiguity of the meaning of the term didakton, which means both "teachable" and actually "taught". Even the attempt to establish virtue on theia moira should be treated with some skepticism. In fact, Socrates alludes at the end of the dialogue, to the possibility that there is a man who is virtuous and who is also able to teach virtue to another man: this extraordinary man is naturally Socrates himself.

KEYWORDS: virtue, knowledge, teachers of virtue, opinion.

se origina graças à reta opinião (orthe doxa) e até por intervenção divina ${ }^{2}$.

Com efeito, a questão de Mênon parece implicar claramente que as opções apresentadas são reciprocamente excludentes, isto é, que se uma é verdadeira, são falsas as outras. Uma tal perspectiva, todavia, não é conciliável com aqueles passos nos quais Platão parece efetivamente apresentar uma cooperação entre os fatores que determinam o surgimento da virtude. Particularmente significativa se apresenta a descrição dos elementos que intervêm na formação dos guardiães no livro II da República, onde dote natural, exercício e educação concorrem na qualidade de fatores cooperantes ao desenvolvimento dos futuros phylakes (Rep. II, 375 e- 376 e). É, pois, provável que a maneira com a qual Mênon coloca a questão da aquisição da virtude dependa da sua perspectiva particular, que não seria correto identificar imediatamente nem com aquela de Sócrates, nem com aquela do autor do diálogo.

Não há dúvida que, formulando a questão em torno da maneira de se adquirir a virtude, Mênon se ligue a um debate que, na última parte do século $V$ devia estar muito aceso ${ }^{3}$. 0 tema da forma de aquisição da virtude e em geral das competências disciplinares estava no centro de um confronto que envolvia sofistas, retores, especialistas das diversas técnicas, e no qual tomaram parte também muitos socráticos, a começar por Xenofonte e a terminar por Críton, que compôs um escrito intitulado Não é possivel tornar-se bons graças à instrução (DL 2.121).

Não há dúvidas que a atitude de Mênon reflete a atitude utilitarista de quem quer imediatamente saber como fazer para obter a virtude, isto é, como veremos, o sucesso e o reconhecimento social. Este aspecto também assinala certamente uma separação entre a perspectiva de Mênon e a de Sócrates. Mênon encarna a figura do jovem que ambiciona 0 sucesso e o reconhecimento público: ele é descrito como prepotente, obtuso, mal disposto a se deixar guiar por Sócrates e o fato que esteja destinado a transformar-se em um tirano feroz constitui o êxito quase inevitável da sua atitude mental. Mênon constitui um péssimo aluno e discutir com ele sobre a virtude devia soar vagamente sarcástico aos olhos de um leitor dos diálogos platônicos atento e informado.

2. 0 Mênon enfrenta, portanto, a questão da aquisição da virtude. Para poder responder à questão com a qual se abre o diálogo, Sócrates convida, para dizer a verdade, com pouco sucesso, o seu interlocutor a indagar em primeiro lugar, o que é a virtude, ou seja, o que é a realidade da qual se quer estabelecer uma característica, isto é, como isto é obtido. No momento em que Sócrates reconduz a questão da maneira de se adquirir a virtude ao problema do conhecimento (definição) da arete, ele parece pressupor o célebre princípio da chamada Priority of definition. Trata-se de uma impostação que originou, sobretudo recentemente, um debate vivaz, concentrado em torno do tema da pressuposta falácia do raciocínio socrático ${ }^{4}$.

Além dos problemas que a questão da prioridade da definição comporta, e que pode conduzir,
2. Este aspecto foi recentemente posto à luz por Blössner (2011) 44. 3. Cf. Barnes (1991) 571-73 e Bonazzi (2010) x-xiv. 4. Uma boa discussão se encontra em Charles (2006). 
segundo alguns estudiosos, a um verdadeiro impasse da indagação (donde o célebre paradoxo da pesquisa seria a expressão mais brilhante), não há dúvida que uma resposta à interrogação sobre a maneira de adquirir a virtude deve comportar uma forma de pré-compreensão da natureza da virtude. Com efeito, a maneira como se pode conseguir a virtude, depende em certa medida do que se entende por virtude: se a arete tivesse a ver com o nascimento e com o pertencimento a um genos particularmente prestigioso, é evidente que ela não seria ensinável e dependeria inteiramente da natureza; ademais, a interrogação com a qual se abre o diálogo pressupõe uma certa unidade da virtude, porque não teria sentido se interrogar sobre a maneira de obter a virtude, se à noção de virtude faltasse unidade ${ }^{5}$. Tudo isso significa que os chamados de Sócrates voltados a individuar um eidos unitário da arete resultam perfeitamente funcionais à solução da interrogação de Mênon.

0 que é então a arete da qual se quer estabelecer a maneira de aquisição? Como universalmente se nota, o termo arete na língua grega não possui ou não possuía primariamente a acepção moral que o vocábulo "virtude" tem nas línguas modernas. A noção grega de arete comporta uma referência à esfera da capacidade de cumprir determinadas prestações; neste sentido, pertence primeiramente ao âmbito prestacional, à performance (por isso também foi proposta, a exemplo de Sharples, a tradução por excellence). 0 seu significado depende portanto do objeto ao qual se refere: a virtude de uma faca resulta radicalmente diferente da virtude de um bailarino ou de um mímico. Exatamente como adjetivo agathos, também o substantivo arete assume um significado diverso, baseado na realidade à qual é aplicado. Não se trata de um termo unívoco, como por exemplo o predicado "azul". De resto, nos mesmos diálogos platônicos podem-se encontrar diferentes ideias de arete: a virtude difundida por Cálicles ou por Trasímaco não é de Pitágoras ou de Mênon, tampouco a de Sócrates, que parece incorporar na noção de arete também um componente "moral".

Dito isso, ou seja, estabelecida a natureza ambígua da noção de "virtude", cabe caracterizar qual seja o significado ativo na discussão entre Sócrates e Mênon, aos quais também Ânito se junta na parte conclusiva do diálogo. Não há dúvida que Mênon tem em mente uma ideia de virtude orientada primariamente em direção à esfera pública e completamente política. Ele pergunta a Sócrates como se pode tornar virtuoso, entendendo com isso saber como se tornar homem público de sucesso, reconhecido e estimado. A discussão com Ânito confirma a orientação política da noção de arete pressuposta pelos interlocutores de Sócrates: com efeito, os exemplos de cidadãos atenienses que se presume terem sido virtuosos (Temístocles, Tucídides, Aristides, Péricles) são todos tirados da esfera política.

Quando Sócrates retoma a ideia de virtude de Mênon, faz referência à capacidade de administrar (dioikeo) as casas e as cidades, desejando evidentemente aludir às características que definem 0 homem de sucesso, reconhecido como tal, dotado de qualidades "práticas" (91 a $)^{6}$. 0 mesmo Ânito concebe a arete como um patrimônio comum que os Atenienses transmitem de geração em geração (92 e). Em outros termos, tanto Mênon como Ânito assumem de modo acrítico uma noção tradicional de virtude, que consiste substancialmente na adequação aos valores compartilhados pela polis.

Para Platão a noção de arete também incorpora um componente político, o qual todavia não é funcional à obtenção do sucesso e do reconhecimento social. Com efeito, a noção platônica de virtude comporta também uma referência à dimensão moral, que assume a forma do conhecimento do bem (e do mal) ${ }^{7}$. Como veremos em breve, um dos aspectos que distinguem a virtude da competência técnica consiste na referência ao bem; se trata de uma referência que torna o conhecimento não só condição necessária, mas também suficiente para a ação moral.

3. Foi dito que a discussão entre Sócrates e os seus interlocutores gira em torno da hipótese que a virtude seja adquirível através do ensinamento. A falha a que se chega na primeira parte do diálogo e as tentativas de Mênon de definir a virtude, unida à sua insistência de querer saber se essa é mais ou menos ensinável, obrigam Sócrates a experimentar 
uma nova aproximação, que consiste no procedimento "por hipótese" (ex hypotheseos). Para ser ensinável, a virtude deve ser conhecimento (episteme), uma vez que o conhecimento é certamente ensinável. Portanto, assumindo-se a hipótese que a virtude seja conhecimento, chega-se em seguida à conclusão que ela é ensinável, e a pergunta de Mênon encontra, assim, uma resposta.

0 método hipotético adotado por Sócrates apresenta a forma de silogismo: (a) a virtude é conhecimento; (b) o conhecimento é ensinável; logo (c) a virtude é ensinável (87 b-c). A hipótese admitida na premissa (a) poderia, por seu turno, resultar na conclusão de um silogismo que apresenta a seguinte forma: (1) a virtude é um bem; (2) o bem é conhecimento; logo (3) a virtude é conhecimento (87 d), no qual (c) [= (3)] é obtida de (1) e (2). A premissa hipotética (1) também deveria ser deduzida silogisticamente da premissa superior, até conseguir-se uma asserção não hipotética, que se coloca no início da cadeia demonstrativa inteira e que seria capaz de transformar um sistema hipotético em uma demonstração incontestável e, portanto, autenticamente dialética ${ }^{8}$.

Não é aqui possível estabelecer se e de que modo Platão considera efetivamente possível identificar e alcançar um princípio anti-hipotético (arché anypothetos) que se coloque no início do sistema das hipóteses. Para o escopo desta questão, é importante concentrar-se no significado da asserção hipotética relativa à identidade entre arete e episteme.

Como se nota, trata-se de uma tese que conhece numerosas formulações no interior dos diálogos de Platão, sobretudo naqueles chamados "socráticos" (cf. p. ex., Laq. 194 d; Grg. 460 b-c; Hip. Mi. 375 d-e; Rp. I.350 d e Prt. 349 d ss.). É então igualmente sabido que a identidade entre virtude e conhecimento representa o núcleo do intelectualismo ético frequentemente considerado como o traço característico da posição socrática ${ }^{9}$. Mas o que significa que a virtude é conhecimento?

Provavelmente esta tese deve ser entendida no sentido que o conhecimento representa juntamente a condição necessária e a condição suficiente do comportamento moralmente virtuoso. Por exem- plo, o conhecimento, mais ou menos definicional, da essência da coragem conduz imediatamente à admissão de um comportamento corajoso. 0 que parece comportar a tese que a força de atração do bem é tal que só o falho conhecimento dele pode gerar o erro moral e, portanto, o vício. Trata-se de um dos célebres "paradoxos socráticos", em torno aos quais existe uma imensa literatura.

Não há dúvida que no Mênon o tema relativo à identidade entre virtude e conhecimento constitui um dos focus do diálogo. A leitura do texto não permite, todavia, obter certezas incontestes tampouco acerca do grau de adesão a ela da parte de Platão.

Antes de tudo, observa-se que Platão parece servir-se dos termos episteme, phronesis, nous e sophia de maneira quase intercambiável ( 88 b; 99 b-c; $100 \mathrm{a})^{10}$. 0 campo semântico destes substantivos é mais amplo, mas não há dúvida que eles parecem referir-se a um tipo de conhecimento que incorpora seja uma dimensão propriamente epistêmica, seja um aspecto competencial e performativo, que os avizinha à techne, seja uma perspectiva de tipo moral, a qual comporta uma referência ao bem. Com efeito, à diferença do saber técnico, o conhecimento moral não é indiferente a respeito do bem, isto é, à esfera dos fins, porque enquanto um technikos que possui uma determinada competência pode decidir aplicá-la ou, do mesmo modo, não aplicá-la, quem possui uma arete, no momento em que conhece o bem, imediatamente o implementa: não existe separação entre theoria e praxis.

0 âmbito ontológico ao qual se endereça a virtude é muito mais difícil de circunscrever que aquele ao qual se referem as técnicas individuais. Cada uma delas se define antes de tudo baseada na delimitação de um campo objetual, que o especialista conhece e sobre o qual então é capaz de intervir. Deste ponto de vista, as técnicas individuais deveriam ser facilmente ensináveis de forma transmissiva, isto é, do modo como um especialista transmite, de forma escrita ou oral, seu patrimônio de saber a um aluno. A existência de manuais técnicos (de arquitetura, escultura, agricultura, música, ginástica, botânica e culinária) ${ }^{11}$ e em geral, de obras de cunho disciplinar (como os tratados médicos do corpus hippocraticum) implica uma ideia transmissiva da
8. A possibilidade que existam uma ou mais assertivas não hipotéticas é negada por Blössner (2011) 54-5. Sobre o método hipotético descrito no Mênon, cf. Fronterotta (2011) 51-54.

9. Uma boa discussão relativa ao intelectualismo socrático encontra-se em Kahn (2008) 223-32.

10. Veja-se a propósito Wilkes (1979) 149. Observações importantes encontram-se em Barnes (1991) 582-86. 11. Cf. Cambiano (1971) 34-36. 
aquisição de saber; trata-se de uma atitude que parece amplamente presente nos próprios sofistas, os quais se apresentavam como mestres da virtude

12. A noção de ensinamento acolhida por Mênon comporta a "passagem" de um conhecimento do mestre para o discípulo e é expressa pelo verbo paradidomi

(93 b). Isso implica uma passividade substancial da parte do discípulo e corresponde ao "método" de ensinamento que Platão atribui aos sofistas. Sobre tudo isso, veja-se Erler (1991)

123-49.

13. Veja-se a discussão em Blössner (2011) 65.

14. Sobre o assim chamado Transmission of virtue problem cf. Perin (2012).

15. Cf. recentemente Ionescu (2005) e Scott (2006)

16. Veja-se a propósito a discussão de Barnes (1991) com réplica de Brunschwig (1991).

política (arete politike) e reuniam em torno a eles tropas de jovens desejosos de receber os fundamentos desta arte.

Com certeza pode-se afirmar que Platão não partilha uma tal ideia de ensinamento, ou pelo menos não acredita que ela seja aplicável ao ensinamento da virtude. Portanto se a virtude fosse efetivamente ensinável, não o seria do mesmo modo que as técnicas. De resto, Sócrates recusa para si mesmo a qualificação de didaskalos e para os seus alunos a de mathetai. São mais os sofistas que concebem a relação educativa na forma de umvínculo entre um mestre (didaskalos), o qual possui um saber, e os alunos (mathetai), que recebem passivamente do mestre determinados conhecimentos disciplinares. Esta "transmissão" toma a forma de uma passagem na qual o receptor assume uma atitude passiva; é como se um líquido fosse transferido de um recipiente cheio para um vazio (Banq. 175 d; cf. também Rep. 7. 518 b-d) $)^{12}$.

Não é, portanto, este o modo como a virtude revela-se eventualmente ensinável para Platão. Sócrates declara isso explicitamente quando, a propósito dos homens mais ilustres e considerados virtuosos, como Péricles e Tucídides, explica que eles enviaram seus filhos a mestres de hípica, de música e de luta, para que retornassem educados, ou seja, recebessem os conhecimentos disciplinares dos respectivos mestres; por outro lado, na virtude (política) não tiveram êxito em educá-los, "talvez porque a virtude não seja ensinável" ou didakton (94 b-d), ou ao menos não o seja como as técnicas.

Não há dúvidas que a concepção de anamnesis, exposta por Sócrates em resposta ao célebre paradoxo do conhecimento formulado por Mênon, tenha também a função de delinear um modelo alternativo de aquisição do saber, um modelo no qual o componente ativo do discente, isto é, do aluno, seja plenamente valorizado. Como se notou, Sócrates chega a identificar explicitamente didakton e anamneston (87 b), aludindo, assim, a um outro modo de ensinar, diverso daquele dos sofistas e dos especialistas nas técnicas particulares. Conforme este modelo alternativo, um mestre não pode ser simplesmente uma fonte de conhecimento, um mero transmissor, mas deve se mostrar como um estimulador; da sua parte, o aluno não pode proceder como mero contentor, mas deve assumir um papel ativo no processo de aquisição do conhecimento e, portanto, da virtude ${ }^{13}$.

4. A hipótese, inicialmente assumida por Sócrates, relativa à identidade entre virtude e conhecimento, da qual decorre a ensinabilidade da arete, é posta radicalmente em discussão e aparentemente mesmo falsificada na base de um célebre e discutido argumento empírico, o qual se fundamenta sobre a ausência de mestres de virtude. Nem sequer os grandes homens de Atenas estiveram em condições de transmitir a virtude (a qual se presume que possuíssem) aos seus filhos (93a - 94 e), o que significa que a virtude não é episteme e, por conseguinte, não é ensinável ${ }^{14}$.

A validade deste argumento foi posta em dúvida por numerosos estudiosos ${ }^{15}$. Com efeito, isso se fundamenta sobre alguns temas aos quais dificilmente Sócrates pode aderir. 0 primeiro refere-se à atribuição da qualificação de homem virtuoso a alguns cidadãos eminentes que marcaram a história ateniense nos decênios precedentes. Uma atribuição semelhante contradiz, no entanto, o que Sócrates assevera explicitamente no Górgias, onde ele nega resolutamente que figuras como Péricles, Temístocles e Símon tenham sido autênticos homens políticos, como demonstra o fato de que não foram capazes de tornar melhores seus concidadãos (Grg. 516 b - $517 c)$.

0 segundo assunto problemático concerne à equivalência, implicitamente estabelecida, entre as noções de "ensinado" e "ensinável": como se nota, em grego, ambas as noções encontram expressão no adjetivo verbal didakton, que indica tanto a possibilidade de ser ensinado, ou seja, uma condição de princípio, como o fato de ser realmente ensinado, isto é, precisamente dado real ${ }^{16}$. 0 ponto crítico da argumentação consiste no problema se a ausência de um dado de fato, isto é, a existência de mestres de virtude e de alunos, possa refutar uma asserção de princípio, vale dizer, a ensinabilidade da virtude. Em outros termos, a circunstância que esta não seja 
de fato ensinada, pode falsificar sua ensinabilidade de direito ${ }^{17}$ ?

0 argumento empírico conduz então Sócrates a corrigir a hipótese inicial, a qual estabelecia a identidade entre virtude e conhecimento, ou de qualquer modo, individualizava no conhecimento a condição simultaneamente necessária e suficiente de obtenção da virtude. A ausência de mestres de virtude induz a avançar na hipótese que o sucesso na ação não se produza só em razão do conhecimento, mas também graças à opinião correta (orthe doxa). Do ponto de vista dos efeitos práticos (pros orthoteta praxeos), isto é, na perspectiva do sucesso operativo, a opinião correta (ou verdadeira) não é guia inferior do conhecimento (96 e - 97 c).

A opinião correta parece possuir um valor instrumental com respeito à ação (política) ${ }^{18}$, porque permite alcançar resultados não inferiores àqueles do conhecimento. Todavia, mantém-se sempre presente que uma tal conclusão se fundamenta na admissão do argumento empírico, cuja validade não pode ser aceita de maneira acrítica. Ademais, não é totalmente dito que a virtude alcançável graças à opinião correta, isto é, aquela virtude que teriam possuído Temístocles, Péricles e os demais, corresponda à autêntica virtude que têm em mente Sócrates e Platão: o sucesso operativo não é automaticamente garantia de comportamento virtuoso. Enfim, segundo o diálogo entre Sócrates e Ânito, nem sequer a virtude obtida por meio da reta opinião é ensinável, na realidade, visto que os Atenienses mais ilustres não estiveram em condições de transmiti-la aos seus filhos; abre-se então o problema relativo ao por que a orthe doxa não seja ensinável ${ }^{19}$.

5. Na parte conclusiva do diálogo, Sócrates resume para Mênon, que neste interregno retomou seu papel de interlocutor, os resultados que emergiram da discussão inteira (98 c- 100 a). A virtude não se forma nos homens por natureza; essa não se origina tampouco graças ao conhecimento, porquanto se demonstrou através do argumento empírico, que ela não é ensinável, a partir do momento que não existem mestres. Portanto a fonte da virtude será constituída pela reta opinião, que representa, junto com o conhecimento, a outra causa da ação correta e útil. 0s homens virtuosos são tais em virtude de uma opinião feliz (eudoxia), isto é, correta, e por isso são similares aos poetas e aos adivinhos, os quais dizem seguidamente coisas verdadeiras, mas sem conhecer verdadeiramente as coisas que dizem (99 c). Portanto a condição dos homens políticos virtuosos seria aquela de quem está de posse da virtude graças a uma sorte divina (theia moira), mas é privado de intelecto (aneu nou: 99 e - 100 a). Mas se assim fosse, o bem, isto é, o útil, que a ação política pode conseguir, não seria controlável e reproduzível, mas se originaria de modo independente do agente moral.

Esta sequência argumentativa reflete efetivamente o ponto de vista de Platão? A resposta a esta questão fundamental só pode ser negativa, como Sócrates mesmo sugere imediatamente a seguir. Ele de fato deixa aberta a possibilidade, no diálogo, nunca tomada em consideração, de que "exista entre homens políticos um que tenha condições de tornar capaz de fazer política também um outro" (100 a). É evidente que este homem excepcional, este único político verdadeiramente virtuoso, existe, e se identifica com Sócrates.

A virtude que ele possui constitui a verdadeira virtude, aquela virtude que se obtém por meio do conhecimento e que é ensinável. 0 seu ensinamento pode advir somente no interior do contexto da autêntica comunicação filosófica, isto é, no interior da prática dialética. Essa consiste, segundo a célebre descrição do Fedro, na capacidade de escolher uma alma adaptada (psyche prosekousa), isto é, autenticamente dotada de uma "natureza filosófica" e na capacidade de comunicar a ela logoi que têm condições de reproduzir-se e de gerar o verdadeiro conhecimento, isto é, a autêntica virtude.

A tese socrática segundo a qual a virtude é conhecimento (e portanto o conhecimento é condição necessária e suficiente para a aquisição da virtude) implica que o conhecimento ético tenha um objeto determinado, o qual se identifica com o bem, mas também que a alma seja plenamente autoconsciente, isto é, implica a consciência de si. A virtude ética representa também o supremo conhecimento de uso, isto é, aquele conhecimento que tem condições de avaliar a utilidade dos outros conhecimentos.
17. 0 argumento empírico assume uma noção fatual de ensinamento, enquanto a interrogação de Mênon deveria referir-se a uma condição de princípio: cf. Dimas (2007) 5. 18. Sobre o valor instrumental da opinião reta cf. Perin (2012) 19. 19. É verdade, como observa Bonazzi (2010) 129 n. 105, que a causa da ausência de mestres de virtude reside no fato que a virtude não é conhecimento e portanto não é ensinável, mas se origina por meio da correta opinião. Todavia o texto não explica claramente por que a reta opinião não seja ensinável; ademais, isso atribui aos homens ilustres a posse de uma virtude que poderia não corresponder à noção platônica de arete. 
Portanto, a virtude socrático-platônica, exatamente como a sophrosyne do Cármides ${ }^{20}$, incorpora três aspectos, entre si inseparáveis: é conhecimento de si (episteme heautes), conhecimento dos outros conhecimentos, e conhecimento do bem e do mal.

Tradução do italiano: Loraine Oliveira

Revisão: Gabriele Cornelli

\section{Referências Bibliográficas}

BARNES, J. (1991) Enseigner la vertu? Revue philosophique de la France et de l'Étranger, n. 116, p. 571 - 589.

BLÖSSNER, N. (2011) The Unity of Plato's Meno. Reconstructing the Author's Thoughts, Philologus, n. 155, p. $39-68$.

BRUNSCHWIG, J. (1991) Pouvoir enseigner la vertu? Revue philosophique de la France et de l'Étranger, n. 116, p. 591 - 602.

BONAZZI, M. (2010) Platone, Menone. Torino, Einaudi.

CAMBIANO, G. (1971) Platone e le tecniche, Torino, Einaudi.

CHARLES, D. (2006) Types of Definition in the Meno. In: JUDSON, L \& KARASMANIS, V. (eds.), Remembering Socrates. 0xford, Clarendon Press, p. 110 - 128.

DEVEREUX, D. (1978) Nature and Teaching in Plato's Meno. Phronesis, n. 23, p. $118-26$.

DIMAS, P. (2007) Teachers of Virtue. Ancient Philosophy, n. 27 , p. $1-23$.

ERLER, M. (1991) Il senso delle aporie nei dialoghi di Platone. Esercizi di avviamento al pensiero filosofico, Milano, Vita e Pensiero, Milano, (orig. Berlin-New York 1987).

FRONTEROTTA, F. (2011) $\pi \mathrm{o}^{\prime} \theta \varepsilon \sigma \iota \varsigma$ e $\delta \iota \alpha \lambda \varepsilon^{\prime} \gamma \varepsilon \sigma \theta \alpha \mathrm{L}$. Metodo ipotetico e metodo dialettico in Platone. In: LONGO, A. (ed.), Argument from Hypothesis in ancient Philosophy, Napoli, Bibliopolis, p. 43 - 74.

IONESCU, C. (2007) Plato's 'Meno'. An Interpretation. New York, Toronto, Roman \& Littlefield Publishers, Lanham.

KAHN, C. (2008) Platone e il dialogo socratico. L'uso filosofico di una forma letteraria. Milano, Vita e Pensiero, (orig. Cambridge 1996).

NEHAMAS, A. (1985) Meno's Paradox and Socrates as a Teacher. OSAPh, n. 3, p. 1 - 30.

PERIN, C. (2012) Knowledge, Stability, and Virtue in the Meno. Ancient Philosophy, n. 32, p. 15 - 34.

SCOTT, D. (2006) Plato's Meno. Cambridge, Cambridge University Press.

SHARPLES, R. W. (1985) Plato, Meno, edited with Translation and Notes, Warminster, Aris \& Phillips Publishers.
WEISS, R. (2001) Virtue in the Cave. Moral Inquiry in Plato's 'Meno'. Oxford, Oxford University Press.

WILKES, K.V. (1979) Conclusions in the Meno. AGPh, n. 61, p. $143-153$.

Artigo recebido em setembro de 2013, aprovado em novembro de 2013. 